\section{SPRU}

Science and Technology

Policy Research
Working Paper Series

SWPS 2013-02

September, 2013

\title{
Grassroots digital fabrication and makerspaces: reconfiguring, relocating and recalibrating innovation?
}

Adrian Smith, Sabine Hielscher, Sascha Dickel, Johan Söderberg and Ellen van Oost 


\title{
SPRU Working Paper Series
}

The SPRU Electronic Working Paper Series aims to accelerate the public availability of the research undertaken by SPRU-associated people of all categories, and exceptionally, other research that is of considerable interest within SPRU. It presents research results that in whole or part are suitable for submission to a refereed journal, to a sponsor, to a major conference or to the editor of a book. Our intention is to provide access to early copies of SPRU research.

\section{Editors}

Tommaso Ciarli

Daniele Rotolo

Associate Editors
Florian Kern
Paul Nightingale
Matias Ramirez
Joe Tidd \&
Carlos Sato
Maria Savona \&
Mariana Mazzucato

Andrew Stirling

Area

Energy
Transitions

Science, \& Technology Policy

Development

Technology Innovation Management

Economics of Technological Change

\section{Administrator}

Jenny Lieu

\author{
J.Lieu@sussex.ac.uk
}

M.Savona@sussex.ac.uk

M.Mazzucato@sussex.ac.uk

A.C.Stirling@sussex.ac.uk

\section{Contact \\ T.Ciarli@sussex.ac.uk \\ D.Rotolo@sussex.ac.uk}

F.Kern@sussex.ac.uk

P.Nightingale@sussex.ac.uk

Matias.Ramirez@sussex.ac.uk

J.Tidd@sussex.ac.uk

C.E.Y.Sato@sussex.ac.uk

uk

(1)

(1)

(1)

\section{Disclaimer}

The works available here are the responsibility of the individual author(s) and do not necessarily represent the views of other SPRU researchers. As matters of policy and practice, SPRU does not endorse individual research contributions.

\section{Guidelines for authors}

Papers shall be submitted in pdf or Word format. They should contain a title, an abstract, and keywords. Papers should be submitted to one of the Editors, who will process them and send them to the appropriate Associate Editor. Two members of SPRU will be asked to provide a short written review within three weeks. The revised versions of the paper, together with a reply to the reviewers, should be sent to the Associate Editor, who will propose to the Editors its publication on the series. When submitting the authors should indicate if the paper has already undergone peerreviewing, in which case the Associate Editors may decide to skip internal review process.

\section{Website}

SWPS: www.sussex.ac.uk/spru/research/sewps

IDEAS: ideas.repec.org/s/sru/ssewps.html 


\title{
Grassroots digital fabrication and makerspaces: reconfiguring, relocating and recalibrating innovation?
}

\author{
Adrian Smith ${ }^{1}$, Sabine Hielscher ${ }^{1}$, Sascha Dickel ${ }^{2}$, Johan Söderberg ${ }^{3}$ and Ellen van \\ Oost ${ }^{4}$ \\ 1 SPRU (Science \& Technology Policy Research), University of Sussex, UK; \\ a.g.smith@sussex.ac.uk; s.hielscher@sussex.ac.uk \\ 2 Institut für Ökologische Wirtschaftsforshung, Berlin, Germany; \\ Sascha.Dickel@ioew.de \\ 3 Institut Francilien Recherche Innovation Société, Paris, France; \\ johan.soderberg@sts.gu.se \\ 4 Science, Technology and Policy Studies, University of Twente, Netherlands; \\ e.c.j.vanoost@utwente.nl
}

\begin{abstract}
Around the world, diverse groups of people are making things together in community-based workshops and their networks. Equipped with versatile digital design and manufacturing technologies, global networks of workshops, like Hackerspaces and FabLabs, provide facilities for exploring 'commons-based, peer-production' in practice; and they are spreading rapidly. Emphasis rests in bringing people into collaborative DIY projects where they innovate and learn together - from making toys and jewellery to solar panels and eco-houses - and use on-line social media to connect to open-source designs, tutorials, and workshops globally.
\end{abstract}

Excited claims are made about workshops transforming practices of design, innovation, production and consumption; "how you live, work and play in a world where anybody can make anything anywhere'. Excitement includes claims for a 'third industrial revolution' and post-consumer sustainable societies. Less evident, however, are social scientific analyses of the practices and governance arrangements actually emerging in workshop spaces and networks, and which could contribute to debate about their possibilities and limitations for sustainability. Some workshops do enable design and innovation for recycling, re-manufacturing, and feeding user-led prototypes into sustainable local enterprise. They might even reinforce virtues relevant to post-consumption societies through peer production, the sharing economy, and collaborative consumption. However, evidence also suggests a dispersal of production capacity, diminished (resource) scale efficiencies, and intensified consumption through the personalisation of manufacturing.

Our paper develops a conceptual framework for analysing workshops. Drawing upon science and technology studies, social movement theory, and material culture, we consider community workshops configuring and performing production and consumption across three inter-connected levels: networkedcommunities, local-workshops, and user-projects. Relationships across these 
levels are complex. When combined with contested ambiguities inherent to sustainable development, then static, life-cycle analyses or similar into sustainability potential is misplaced. Rather, workshops constitute dynamic spaces for experimentation, and it is the emerging capabilities and material cultures that are most significant for aspirations to post-consumer societies.

\section{Introduction}

Throughout the history of modern environmentalism, 'innovation' has been evoked as a key for unlocking more sustainable developments. Whether it is in terms of stretching and redefining the limits to growth (Cole, Freeman et al. 1973), the ecological modernization of industries (Spaargaren and Vliet 2000; McLaughlin 2012), grassroots innovation (Bookchin 1967; Hess 2007; Seyfang and Smith 2007), or in other spheres, the spread of alternative social and technological configurations for production and consumption appears paramount (Pepper 1984).

More recently, rapid advances in digital design and fabrication technologies are creating radical new possibilities for innovations in production and consumption (Birtchnell and Urry 2012). Individuals, firms, and grassroots groups are experimenting with these possibilities in ways that raise questions about reconfiguring, relocating and recalibrating innovative capabilities in society. Reconfiguring, because grassroots groups, social enterprises, and citizenconsumers are accessing new innovation capabilities and becoming involved in novel production activities; relocating because digital fabrication enables widely dispersed, yet localized, grassroots innovation that spreads collaboratively through networks involving social media and physical meeting places; and recalibrating because as well as permitting grassroots innovation, digital material capabilities are being mobilizing for normative social purposes, such as commons-based peer-production ${ }^{1}$ and sustainability.

This working paper introduces grassroots digital fabrication, and develops a conceptual framework for analysing whether and how activity in 'makerspaces' opens new niches for sustainable innovation in society. It represents our initial thoughts in a research project into grassroots digital fabrication that aims to advance scholarship that has practical value. Our research aims to:

Gain a thorough empirical and theoretical understanding about grassroots digital fabrication practices, organisation and infrastructure; Develop multi-level methodologies capable of analysing the complex, processes of grassroots innovation rooted in social movement theory and sociology of technology;

Analyse the tensions, possibilities and limitations of grassroots digital fabrication for normative goals of sustainability, inclusion and creativity;

\footnotetext{
${ }^{1}$ Commons-based peer-production is wide-scale, self-organised collaboration between large numbers of people in the development of meaningful projects (usually with the help of Internet social media). This is in contrast to firm/hierarchical and market/exchange production. An example is the on-going development of the RepRap 3-D printer.
} 
Advance new social theory for grassroots innovation in society;

Deliberate with practitioners and policy-makers the implications of this movement for innovation policy and governance.

We welcome feedback!

The topic has significant intellectual and practical implications. High-tech capabilities are spreading into grassroots movements internationally. At the same time, digital fabrication articulates very localised activity that requires indepth study on the ground. Research needs to be carefully designed to combine access to local practices on the ground with analysis of norms forming through international digital fabrication networks.

The paper is structured as follows. Section two introduces grassroots digital fabrication, some of the claims being made for these developments, and critical issues regarding the framing of sustainability, inclusion and creativity. Section three discusses how theories of social movements and the sociology of technology can help us understand the various framings and their materialisation within workshop practices. In section four, a conceptual framework is proposed for analysing how framings might manifest across networks, workshops and projects. We conclude by suggesting research in this vein will allow a deeper sense of the material cultures and hence (un)sustainabilities opening up through grassroots digital fabrication.

\section{Framing grassroots digital fabrication}

The confluence of digital fabrication technologies (e.g. the 3-D printing 'revolution'), new business models (e.g. 'personalised manufacturing'), and grassroots movements (e.g. 'makerspace' community workshops), is prompting some excitement. Emphasis rests in people joining collaborative manufacturing projects where they innovate and learn together; and using on-line networks to connect to open-source designs, tutorials, and workshops globally. Speaking at the launch of Manchester 'FabLab', ${ }^{2}$ Neil Gershenfeld from Massachusetts Institute of Technology claimed, 'the real project is not specifically the tools, but ... in asking how you live, work and play in a world where anybody can make anything anywhere.' In the media, The Economist (21/4/12), BBC and others report 'collaborative manufacturing' will revolutionise innovations in production and consumption (Stangler and Maxwell 2012).

Practitioners use a variety of terms to describe community-based digital fabrication facilities: "coworking spaces", "innovation laboratories", "media labs", "fablabs", "hacklabs" and "hackerspaces". Whilst these names indicate various activities and suggest degrees of community involvement, the definitions overlap

\footnotetext{
${ }^{2}$ A community-based digital fabrication workshop receiving more than 3000 users since opening in 2010 .
} 
in practice and are debated. ${ }^{3}$ For the sake of clarity, we name our object makerspaces. These are community-oriented spaces dedicated to grassroots digital fabrication. They provide members of the public with physical environments where they can experiment and learn with others through handson involvement in self-directed projects. Hackerspaces, FabLabs and their networks are prominent. There are 1330 Hackerspaces and 189 FabLabs globally and numbers are growing rapidly. ${ }^{4}$

These makerspaces provide a suite of digital design and manufacturing technologies, including 3D printers, open-source and web-based design tools, electronics kits, vacuum formers, computer controlled milling machines, welding equipment, sewing machines, and laser cutters. The variety of materials and complexity of fabrication expands, and knowledge systems and digital interfaces are easing user engagement. Open source designs (e.g. instructables.com), allow users to modify, personalise and manufacture anything from toys and vehicles to solar panels and eco-houses. Makerspaces are networked through on-line social media (connecting them to designs, tutorials, debates and a movement of makerspaces globally), and through national, regional and international events (e.g. Maker Faires, Open Hardware Summits, etc).

The following narratives are particularly prominent amongst commentators and practitioners. Each frames differently the sociotechnical possibilities of grassroots digital fabrication:

A 'third industrial revolution' extending the digital revolution of ICTs and social media into the material world (Anderson 2012; P2P Foundation 2012);

A 'democratisation of manufacturing' as citizen-consumers engage in commons-based peer-production (Benkler and Nissenbaum 2006; Mota 2011);

Unlocking 'grassroots innovation' and entrepreneurship through accessible digital fabrication (Gershenfeld 2005; Troxler 2010); and,

More 'sustainable production and consumption' through local provision, remanufacture, and the material cultivation of post-consumerist values (Schor 2010; Albinsson and Perera 2012).

Some narratives connect readily to policy agendas for digital economy, advanced manufacturing, and inclusive innovation. Public investment is justified in terms of user-led innovation, skills, entrepreneurship, and economic regeneration (Manyika, Sinclair et al. 2012; Stangler and Maxwell 2012). Other narratives derive from activism and connect digital fabrication to social movements for

\footnotetext{
3 "FabLabs" stand out in providing a standard model pioneered by Massachusetts Institute of Technology (MIT), but openly available to adaptation by all.

${ }^{4}$ Hackerspaces in selected countries number USA: 554 (appr.); Germany: 128; France: 51; UK: 59; NL: 29 (hackerspace.org; accessed 16/01/2013). FabLabs in our study countries number: USA: 40; France: 29; Netherlands: 18; Germany: 11; UK: 5. Members and users of individual makerspaces range from the tens, through the hundreds, to the thousands in some cases.
} 
commons-based peer-production, hacking, and sustainability alternatives (Bauwens 2013; Wark 2013).

Advocates of the latter argue that commons-based peer-production has an affinity with principles of environmental sustainability and social justice, and that digital fabrication in that form will permit more sustainable production and consumption (Bauwens 2013). Digital fabrication is seen as enabling people to re-connect with production at a community-scale. Decentralised workshops could permit co-operation in closed-loop, local economies, and the reinterpretation of what is needed and should be provided for (Schor 2010). The possibilities for personalised production and consumption opens more meaningful possibilities for designing good and services for longevity and durability (Anderson 2012). Some workshops do enable design and innovation for recycling, re-manufacturing, and feeding user-led prototypes into sustainable local enterprise. They might even reinforce virtues relevant to post-consumption societies through peer production, the sharing economy, and collaborative consumption.

None of these framings of possible radical innovations in production and consumption are particularly new in debates about post-consumerist material cultures, including issues of inclusivity and democracy, decentralisation and resource efficiency potentials and discussions of more creative, less alienating technologies (Bookchin 1967). Community-based provision practices through the use of machine tools have been a feature of modern environmentalism discourses for a while. For example, Mike Cooley, who came to prominence through his involvement in the Lucas Plan for workers control over socially useful production in the 1970s (Wainwright and Elliott 1982), argued computerassisted machine tools could be developed in ways that not only respected and enhanced operator skills, but that could accompany industrial democratisation over alternative strategies for socially useful production (Cooley 1987).

However, the technological possibilities within digital fabrication might rekindle these framings in interesting new ways. Technology is situated in a set of desired social relations in which features of digital fabrication make it reasonable to expect reconfigurations, relocations and recalibrations of innovations in production and consumption: its scale, its versatility, its controllability, its modularity, its inter-connectedness, its openness, and so forth. New practices and governance possibilities open up. However, many advocates (though not all) are also aware that the overall socio-technical configuration is not inherent to the technology. The technologies may reveal affordances for sustainable production and consumption in forms that are inclusive and creative, but such practices are neither inherent nor inevitable: wider society shapes the kinds of technology in use, as well as their uses.

Indeed, there are opposite possibilities for digital fabrication, and which introduce tensions informative for whether and how grassroots digital fabrication is relocating, recalibrating, and reconfiguring innovative capabilities in society. 
The first issue is sustainability, and whether and how grassroots digital fabrication recalibrates innovation. As the visions above recognise, materially, digital fabrication enables re-localisation of production-consumption, and the re/up-cycling of materials in local systems (Schor 2010); culturally, productive participation is argued to cultivate post-consumerist values and longevity in goods through stronger associations with the objects produced by participants (van Hinte 1997; Verbeek 2006; Bauwens 2013). But consumption might also intensify through throw away, personalised fabrication (Marston 2011). Diminished scale efficiencies could intensify resource use, rather than reduce it, as well as disrupting waste collection and reprocessing infrastructures. So sustainable digital fabrication is not automatically inscribed into makerspaces.

The second issue is inclusivity, and whether and how grassroots digital fabrication reconfigures innovation. Digital fabrication is accessible for user-led and grassroots innovation. Despite surveys indicating individual users being predominantly male and university-educated (Moilanen 2011), grassroots initiatives, like the FabLab experiment at Sustainable South Bronx, try deliberately to cross the digital divide and empower people through the innovation capabilities presented by digital fabrication. However, as well as potentially empowering, digital fabrication extends concern about labour exploitation, as users create open innovations susceptible to appropriation by firms (Scholz 2013), and as suggested by the growing use of design challenges, prizes and user-led firms like Quirky.

The third issue is creativity, and whether and how grassroots digital fabrication relocates innovation. The learning, skills, ideas and networks people acquire through involvement in digital fabrication are important means by which grassroots innovation capabilities develop. And yet, studies historically have debated whether managerial introduction of numerically controlled (later computer-controlled) machine tools in industry de-skilled and dis-empowered operator initiative (Noble 1984; Jones 1997; Soderberg 2012). Does grassroots digital fabrication imply a restricted or a transformational reclaiming of these technologies for creativity?

These possibilities and critical issues will be familiar to students of innovation in society (such as science \& technology studies), and where complex and ambivalent relationships between the material characteristics of technological artefacts and their social construction into working technologies has been a longstanding focus of analysis and debate.

\section{Examining makerspaces through theories of socio-technical framing}

Grassroots digital fabrication sits awkwardly with conventional innovation theory. Ideas about innovation proceeding through interactions between the institutions of firms, R\&D centres, entrepreneurship, investment, and public policy are insufficient (Nelson 1993; Freeman and Soete 1997). For sure, conventional 'innovation systems' remain important. The 'regime of 
technoscientific promises' is still a core feature of innovation in society (Expert Group on Science and Governance 2007). However, in order to gain a more complete understanding of innovation processes we need to develop theory centred on innovations taking place in the broader field of society. As much is suggested in the growing interest amongst researchers, policy advisors, think tanks, media outlets, and others in the topics of grassroots innovation, usercentred innovation, open innovation, social innovation, frugal innovation, grassroots innovation, and community innovation. Proliferating adjectives reflect the fact that the agents, arenas, agendas, and processes of innovation are opening up in society (Elliott \& Turner, 2012). New sociotechnical reconfigurations, relocations and recalibrations of innovation are unfolding, with implications for the forms, scale and distribution of innovation processes and their outcomes (Joly, Rip et al. 2010). The European Expert Group on Science and Governance calls this emerging (niche) space 'collective experimentation'. But what lies underneath these patterns? The makerspace movement is playing an integral part in developing grassroots capabilities for innovation and is seeking to propagate them through society.

In order to generate new insights and develop theory, we explain why analysis must reach beyond recent scholarship in user-led innovation, and draw upon ideas about framing in social movement theory and the sociology of technology and ideas about wider societal influence of grassroots experimentations in niche theories.

\section{Beyond user-led innovation theory}

Scholarship in user-led innovation brings a variety of perspectives to different aspects of the topic: from user-motivations to innovate, to firm strategies to appropriate inputs from users (Von Hippel and Katz 2002; von Hippel 2005; Chesbrough, Vanhaverbeke et al. 2006; Hienerth 2006; Braun and Herstatt 2008; Dahlander and Gann 2010; Heiskanen, Hyysalo et al. 2010). ${ }^{5}$ Despite this rich variety, the innovation subjectivities and processes opened up by user-led perspectives still tend to under-theorise the role of communities in fostering innovation processes (West and Lakhani 2008). The community is often assumed to be an empty space where users exchange ideas, while the analytical focus is on individual motives for sharing. However, as 0'Mahony has demonstrated, the sharing practices cannot be understood apart from the norms upheld by the community (O'Mahony 2003).

A characteristic feature of makerspaces is that they develop under a tension between individualistic, entrepreneurial projects and collective, community-

\footnotetext{
${ }^{5}$ Firms are opening to user-led digital fabrication, whether through competitions, releasing designs, or commercialising grassroots innovations. Nokia allows users to manipulate code and 3-D print their own phone cases. Quirky takes popular user designs selected through social media, releases 3-D printing and prototyping with other users, and rapidly markets the products through the internet social networks built as part of the innovation process.
} 
based activities (Siefkes 2007; P2P Foundation 2012). ${ }^{6}$ Material support for makerspaces comes from a variety of sources, including local authorities, skills and enterprise agencies, charities, and commercial sponsorship, alongside membership and volunteer contributions. Some makerspaces are required, for funding purposes, to engage in 'closed' consultancy and entrepreneurial activities, often on alternative days to open, community-oriented activity. This incorporates negotiating intellectual property when rapid prototyping for clients. Whilst potentially helpful to the flow of innovations between the informal and formal, this juxtaposition of a conventional regime of innovation can prove controversial and challenging alongside more niche commitment to openness and commons-based peer-production (Currah 2007). Issues of social inclusion in innovation clash between users following individualistic, entrepreneurial forms and activists seeking collective norms of commons-based, peer-production.

A fuller understanding of grassroots innovation consequently requires the development of theory centered on the community seen in its dynamic life-cycle process. Such inquiry poses questions about the identity, the goals, and perceived threats and opportunities constitutive of the community (Seyfang and Smith 2007). A more sociological account of the different 'framings' of grassroots innovation in play in makerspaces will provide a more fruitful analysis. Here, theories from social movement studies and the sociology of technology can help (Smith 2005; van Oost, Verhaegh et al. 2009; Söderberg 2011).

\section{Technology-oriented social movements}

Social movement theories conventionally explain either social mobilizations seeking rights from political and social institutions, or alternative identities and counter-cultural forms in the context of socio-economic change (Darnovsky, Epstein et al. 1995; Snow, Soule et al. 2004; Kolb 2007). Whilst social movements resisting technologies form a sub-field (Bauer 1995; Smith 2005), the analysis of movements as agents of innovation is less common (Cole, Freeman et al. 1973; Jorgensen and Karnoe 1995; Jamison 2003; Smith, Fressoli et al. 2013).

Technology-oriented movements are less overtly about the politics of protest and more focused on 'building and diffusing alternative forms of material culture' (Hess 2005): 516; also (Marres 2012). In doing this, however, movements encounter and have to accommodate other actors key to technology development, such as industrial reform movements in the private sector attracted to the same alternative technologies, but differently interested in commercial rather than social benefits. Movements have to develop positions and strategies over the incorporation and transformation of technologies by reform interests, and engage in 'object conflicts' about fragmenting norms and directions of innovation (Hess 2007). The history of the free software movement

\footnotetext{
${ }^{6}$ Diversity ranges from makerspaces committed to radical DIY and sustainability positions through to makerspaces linked to institutions for skills, entrepreneurship and regeneration.
} 
and its development into open source business models is a relevant example (Wark 2013).

Pertinent to contests over the meanings and manifestations of digital fabrication are issues of identities, spaces of mobilisation, and their framings of technology. This suggests makerspaces be understood in terms of the sources and processes through which common identities in digital fabrication are formed, including the micro-contexts of common experience in projects (Snow, Rochford et al. 1986; McAdam 1988). For example, what holds makerspaces together (even if temporarily) and informs attitudes and responses to 'user-led' appropriations by firms?

A movements-oriented analysis emphasises the content and operation of makerspace networks. It explains developments through the interplay of space, power, framings and resources (Miller 2002; Coleman 2010). Multi-layered networks link participants in diverse local sites across global spaces (Edelman 2001). Information technologies help forge not so much a common agenda, as broad issue framings which permit the sharing of ideas and activities for relocalisation in forms that suit specific contexts, problems, needs and priorities (Appadurai 2000; Leach, Scoones et al. 2005).

Sociotechnical framings are particularly important for technology-oriented movements: the interrelations of mobilisation and framing through particular ideas, meanings and moral stances towards digital fabrication (Benford and Snow 2000; Smith 2005). Activism therefore involves not just the assertion of an agenda, but rather contests to cultivate certain sociotechnical configurations (McAdam, Tarrow et al. 2001; Crossley 2002). Clashes between framings can be protracted and resolutions far from straightforward (Hess 2007; Smith 2007). The tensions identified earlier in sustainability, inclusion and creativity will be recognised, prioritised and addressed differently, depending upon the framings influencing grassroots digital fabrication.

\section{The social construction of technology}

Theory about social movement framings connects with ideas about 'technological framing' in the sociology of technology (MacKenzie and Wajcman 1985; Hess 2005; Smith 2005). The co-productive powers of the social and material is emphasised in processes of sociotechnical configuration (Wajcman 2002; Oudshoorn and Pinch 2003; Jasanoff 2004; Bijker 2010). Digital fabrication technologies in makerspaces have certain 'technical' characteristics 'scripted' into their design and operation (e.g. the range of materials they can work, the scale of operations possible, a digital-orientation to craft processes) (Akrich 1992), but important social processes affect their performance and consequences (MacKenzie and Wajcman 1985; Bijker and Law 1992).

Makerspaces share a fairly similar cluster of technologies and broadly comparable approaches to training and cultivating skills. Understanding the way social processes interact with this material basis to co-produce different sociotechnical configurations of digital fabrication (and hence innovation 
possibilities) becomes paramount. All framings will involve value judgements and interests, giving priority to certain issues over others, and containing various possibilities for grassroots innovation. Analysis must engage the actors and networks producing these different framings, and attempting grassroots innovation differently in society. So, for instance, tracing whether and how funding from universities and enterprise agencies is framed, and whether and how this shapes the provision of skills and innovation capabilities, compared to the framings of makerspace activists and advocates of commons-based peerproduction.

Technological frames arising through these social interactions orientate sociotechnical development in terms of issues, strategies, requirements, theories, knowledge, procedures, user practices, and exemplary artefacts (Bijker 1995). Constructivist methodology originally identified frames solely from statements amongst 'relevant' social groups. Recent moves towards a co-productive view incorporate material culture into framing processes (Bijker 2010). Analysis must attend to the way people engage materially with digital fabrication, and how observed practices shape, enable and underpin the formation, validation or unsettling of different frames (Dant 2005; Miller 2005; Atkinson 2006; Watson and Shove 2008). Consequently, understanding grassroots innovation through the way different 'framings' influence sociotechnical capabilities to innovate can be identified by iterating between narratives about makerspaces and material practices in makerspaces.

Whilst makerspaces might appear relatively marginal and powerless compared to incumbent systems of production and consumption, it is noteworthy that some deep structural changes are generative for this movement (Buechler 2000), allowing a material (re)turn sociologically, politically and philosophically. Whilst the radically visionary narratives introduced earlier need to be treated with caution, they do connect with and seek to frame and mobilise material possibilities for opening up new forms of innovation. Some theorists anticipate 'closure' negotiated around certain frames, and leading to obduracy and trajectories of sociotechnical development (Bijker 1995), other contributions argue this need not be inevitable. A plurality of frames can contest and re-shape sociotechnical configurations (Khoo 2005). Other analysts argue the relative influence of different framings is shaped by structures of social, economic and political power (Winner 1993; Leach, Scoones et al. 2010).

Observing an unusual convergence in participatory design practices, Asaro (2000) delineated the uncertain flexibilities in developing new technologies and their corresponding socio-technical arrangements:

"Unlike human political agents, technology does not challenge norms as illegitimate, but as unworkable. There is a danger of confusing this notion with a common assumption of techno-rationalism-that the technology itself imposes a logic on discourse. This is not what is meant by considering technology as an agent. Technologies are certainly open both to application and development, and are thus not inflexible to the political will. But neither are they infinitely flexible and perfectly plastic. Some configurations work, some cannot work, and many 
others may remain uncertain. Specific technologies may or may not be possible, and the only way to arrive at a legitimate conclusion is to pursue research, and thus commit resources, into exploring those possibilities." (Asaro 2000)(p.288)

Grassroots digital fabrication can be conceived as doing precisely that: grassroots groups are experimenting with technological possibilities, and exploring whether and how they are workable for the purposes of commonsbased peer-production, sustainability, inclusivity, hacking, fun, inquisitiveness, skills acquisition, creativity, or whatever other framings the groups deem to be legitimate.

Innovations within makerspaces and their combination with developments in the wider social world

Considering grassroots digital fabrication groups as initiatives that experiment with technological possibilities, makerspaces can consequently be conceived as a 'niche space' in which groups grapple with the framing issues above. Such a conceptualisation follows approaches for analysing purposeful socio-technical transformations in society (Kemp, Schot et al. 1998). Makerspaces provide resources and constituencies for grassroots digital fabrication ideas and practices where more conventionally commercial production and consumption settings do not (Hoogma, Kemp et al. 2002). The question is whether and how innovations arising under (some of) the framings above might translate into more conventional settings, and even become seeds for wider transformations in conventions along the lines envisaged by advocates quoted earlier, and depending upon their combination with developments in the wider social world (Truffer 2003; Geels and Schot 2007; Smith 2007).

Under this view, makerspace networks provide links between specific makerspaces and projects that permit new forms of innovation to flow and mobilise. So, for example, on-line forums, conferences, and distance learning academies help in the dissemination and development of commons-based, peerproduction practices. Makerspace networks provide important physical and social infrastructure, and they render outcomes mobile, replicable and communicable (Star 1999).

An important element to 'niche' approaches is the way networks draw upon local experimentation in order to mobilise wider expectations, about digital fabrication. Projects like the FabLab eco-house ${ }^{7}$ have become widely communicated as emblematic of and for grassroots digital fabrication. Makerspace advocates seek to represent the innovation influentially to the wider social world - often through the exploitation of opportunities driven by wider processes (Smith and Raven 2012). Contributors to a recent special issue of Innovations (2012; 7, 3; 'Making in America') attempted precisely these moves when connecting makerspaces to policy interest in reinvigorating manufacturing in the context of economic crisis (Stangler and Maxwell 2012).

${ }^{7}$ http://www.fablabhouse.com/en/ 
At the same time, the potential influence of this practical experimentation and the diversity of makerspaces throw up questions about what it means to practice commons-based peer-production or to be sustainable. Analytical interest is in whether, how, and why issues of sustainability, inclusiveness and creativity are debated, manifest or confounded in (re-)framings of grassroots digital fabrication, and what this means for the innovation capabilities being cultivated and their combination with developments in the wider social world.

How are grassroots groups grappling with sustainability issues, and how might they recalibrate innovation for sustainable material cultures?

How are grassroots groups grappling with inclusivity issues, and how might they reconfigure more empowered roles in innovation?

How are grassroots groups grappling with this issue, and how might digital possibilities relocate creativity in grassroots innovation?

Social scientific research can help makerspaces reflect upon and further explore possibilities, as well as inform policy-makers on the kinds of support most appropriate for such diverse activity. In order to do this, we need to better understand the workshops and the networks created by grassroots groups, and where experimentation with technological possibilities and exploration of critical issues are discussed.

\section{Towards a conceptual framework for analysing makerspaces}

An advantage with makerspaces is that participants are generally reflective about their involvement and openly debate it within online forums and training programmes. This generates a particularly rich evidence base for developing theory about the deeper causes, forms, and consequences of grassroots innovation in society. Moreover, any difficulties in the practical manifestation of digital fabrication narratives, and evident in this conducive setting, are likely to be valid in other, less conducive societal settings. Conversely, because of the diversity of makerspaces across varied local contexts, then any framings, practices and governance arrangements common across them suggest features of more fundamental relevance to grassroots digital fabrication (Eisenhardt 1989; Flyvbjerg 2006).

Exploring the formation of these framings, practices and governance arrangements, a research methodology that studies makerspaces must attend to the interrelations between narratives about these spaces and material practices displayed in them. Framings of social processes and technologies form over time and are influenced by the way people engage materially with digital fabrication, as these practices shape, enable and underpin the formation, validation or unsettling of different narratives. Combinations of material and discursive elements in framings can be distinguished from one another in the way they configure practices and innovation capabilities differently, including issues, meanings, strategies, requirements and exemplary artefacts. They manifest themselves within makerspace networks, workshops norms and specific 
production-consumption projects, and that each provides in turn an important physical and social infrastructure in which these practises and framings can be reproduced and observed.

Makerspace networks provide links between specific makerspace workshops and projects that permit forms of identities and innovations to flow and mobilise. So, for example, online forums, conferences, and distance learning academies help in the dissemination and development of commons-based, peer-production practices and framings. In addition, networks (including workshops and projects) help makerspace advocates to represent existing framings and practices coming from digital fabrication as being influential to the wider social world. All this suggests a methodology that studies makerspaces as constituted by multi-level interactions (between projects, workshops and networks). Framings of grassroots digital fabrication arise through interactions across these three different levels:

Networked-communities level: where the analytical focus rests in grassroots digital fabrication social movements

Local-makerspaces level: where the focus is in the organisation and governance of physical workshops in local communities

User-projects level: where the focus is innovative projects conducted in workshops

At the networked-communities level, analysis needs to understand how different grassroots digital fabrication narratives are mobilised and made meaningful in blogs, on-line discussions, forums (e.g. hackerspaces.org), and events (e.g. FabFuse 2012). The skills, images and identities promoted through networked-communities via on-line training programmes (e.g. FabAcademies), videos, and databases (e.g. Instructables) can be studied. What shapes the different framings identified in networked-communities needs explaining, as well as understanding how those framings shape the 'infrastructure' provided by networks to local-makerspaces and user-projects. Theory suggests explanations will involve: the structural opportunities and challenges affecting different framings of grassroots digital fabrication; the identities evoked in different framings and the strategies and mobilisations around them; the spaces where engagement arises with material digital fabrication in terms of the form and provision of 'infrastructure' for makerspaces; and how issues of sustainability, inclusion and creativity.

The local-makerspaces level will comprise a wide variety of different kinds of workshop. Sources of diversity include: declared commitments to sustainability, inclusion and creativity; prominent in networked-communities (so that network linkages can be explored); relatively established (so that they have a history of practice); located in different socio-economic districts (locational diversity); different institutional links and governance frameworks (organisational diversity). The mission statements for workshops will indicate their own attempts at framing, and will probably reflect some frames within the wider movement, as well as informing how the space is governed, and characteristics of the space as experienced by those undertaking projects. 
Analysis at the local-makerspaces level needs to explain framing affects upon the governance of local-makerspaces. Interviews and focus group analysis are methods that can explore how ideas about digital fabrication discussed in makerspaces manifest in material projects, and conversely how project activities influence makerspace framings. Of particularly interest here is how makerspaces manage relationships between different framings, and the resolution of any tensions between these and imperatives from different forms of institutional support. Similarly, the influence of networked-communities in these processes, and conversely how makerspaces engage with networked-communities and contribute to framings at that level.

Ethnographic study at the user-projects level, particularly those that prioritise sustainability, inclusion and creativity, provides deeper, contextually rich analyses of the extent to which makerspace practices can be configured for sustainability in relation to the framings evident in local-makerspaces. Analysis of user-projects can uncover the varied motivations of participants, how they identify with digital fabrication, and how their engagement with makerspace communities has evolved (including skills acquisition and evidence of normative commitments). Relations between projects and the life and facilities of the localmakerspace, as well as evidence for links to networked-community framings, such as on-line training, designs, and debates. Analysis of user-projects is particularly important to explaining the materiality of framings.

Synthesis towards social theory of grassroots digital fabrication can then proceed by clustering and inter-relating the different framings across the different levels and contexts. The approach is illustrated in table 1. Analysis for multi-level articulations of framings can explore how the operation of framings identified at each level, including evidence for the narratives and issues introduced earlier, are influencing the organisation and operation of the other levels, and vice versa.

Table 1: inter-relating makerspace levels

\begin{tabular}{|c|c|c|c|}
\hline \multirow[b]{2}{*}{ (Focal level) } & \multicolumn{3}{|c|}{ (->How do the other levels contribute to the focal level?) } \\
\hline & User-projects & Local-makerspaces & $\begin{array}{l}\text { Networked- } \\
\text { communities }\end{array}$ \\
\hline User-projects & $\begin{array}{l}\text { User-project framings of } \\
\text { digital fabrication: what } \\
\text { issues, meanings, } \\
\text { strategies, requirements, } \\
\text { exemplars and practices } \\
\text { do we see in user- } \\
\text { projects? }\end{array}$ & $\begin{array}{l}\text { How do local-makerspaces } \\
\text { facilitate and shape user- } \\
\text { projects? } \\
\text { What forms of user-project } \\
\text { are privileged, and why? }\end{array}$ & $\begin{array}{l}\text { How do networked- } \\
\text { communities facilitate } \\
\text { and shape user- } \\
\text { projects? } \\
\text { What forms of user- } \\
\text { project are privileged, } \\
\text { and why? }\end{array}$ \\
\hline $\begin{array}{l}\text { Local- } \\
\text { makerspaces }\end{array}$ & $\begin{array}{l}\text { How do user-projects } \\
\text { constitute the activity } \\
\text { and identity of local- } \\
\text { makerspaces? } \\
\text { How do user-projects } \\
\text { affect local-makerspace } \\
\text { governance? }\end{array}$ & $\begin{array}{l}\text { Local-makerspace } \\
\text { framings of digital } \\
\text { fabrication: what issues, } \\
\text { meanings, strategies, } \\
\text { requirements, exemplars } \\
\text { and practices do we see in } \\
\text { local-makerspaces? }\end{array}$ & $\begin{array}{l}\text { How do networked- } \\
\text { communities help } \\
\text { local-workshops } \\
\text { operate? } \\
\text { What influences do } \\
\text { networks have over } \\
\text { local workshop- } \\
\text { governance? }\end{array}$ \\
\hline
\end{tabular}




\begin{tabular}{|c|c|c|c|}
\hline $\begin{array}{l}\text { Networked- } \\
\text { communities }\end{array}$ & $\begin{array}{l}\text { What kinds of user- } \\
\text { projects become iconic } \\
\text { for network- } \\
\text { communities? } \\
\text { How do practices } \\
\text { cultivated through user- } \\
\text { projects } \\
\text { correspond/clash with } \\
\text { the ideals and visions for } \\
\text { innovation in the } \\
\text { movement? }\end{array}$ & $\begin{array}{l}\text { Why are some local- } \\
\text { makerspaces more } \\
\text { prominent in networked- } \\
\text { communities than others? } \\
\text { How does local- } \\
\text { makerspace diversity help } \\
\text { or hinder networked- } \\
\text { community activities? }\end{array}$ & $\begin{array}{l}\text { Networked- } \\
\text { community framings } \\
\text { of digital fabrication: } \\
\text { what issues, } \\
\text { meanings, strategies, } \\
\text { requirements, } \\
\text { exemplars and } \\
\text { practices do we see in } \\
\text { networked- } \\
\text { communities? }\end{array}$ \\
\hline
\end{tabular}

Explanations for the development of grassroots digital fabrication can be sought through the different articulations between framings across levels, how those articulations are generated and sustained, and how those articulations influence innovation subjectivities, processes and consequences.

\section{Conclusions}

Independent, social scientific analysis into developments in grassroots digital fabrication is only beginning to emerge. ${ }^{8}$ Beyond practitioner aspirations, significant questions remain unanswered as to whether and how the 'sociotechnical framings' claimed for digital fabrication are manifesting in realities on the ground, and what this potentially radical transformation actually means for innovation in society. Research needs to compare and contrast the possibilities claimed for grassroots digital fabrication with what people are practicing for themselves on the ground. Social theory for grassroots innovation in society is required that provides insight for practitioners, observers and those interested in the governance of innovation for sustainability.

Background theories suggest that digital fabrication transforms grassroots innovation capabilities in society through the interaction and operation of a variety of new framings. In this paper we have suggested a way of exploring 'makerspaces' as a particularly rich site of experimentation with different framings. The influence of these framings works through multi-layered networks of actors whose processes operate across differently located sites, and develop through the identifications and material practices of participants. Whilst important structural settings affect the broad opportunities available, it is movement and technological framings that negotiate and realise grassroots innovation capabilities, including for sustainability, inclusion and creativity. Any advances in social theory for grassroots innovation will need to explain the plural and contested ways in which digital fabrication is opening up grassroots innovative capabilities in society.

\footnotetext{
${ }^{8}$ For example, two panel sessions on Hackerspaces at the 4S/EASST conference at Copenhagen in 2012 presented a number of case studies into specific spaces.
} 


\section{Acknowledgment}

This paper develops a research proposal we submitted to an Open Research Area call in 2012. Dave Conz at Arizona State University was part of the proposal team. Dave contributed many insightful ideas, and lots of fun and enthusiasm. We were all looking forwards to working with him. Tragically, he died soon after we submitted the proposal.

\section{References}

Akrich, M. (1992). The de-scription of technical objects. Shaping Technology / Building Society: Studies in Sociotechnical Change. W. E. Bijker and J. Law. Cambridge, Mass., MIT Press.

Albinsson, P. A. and B. Y. Perera (2012). "Alternative marketplaces in the 21st century: Building community through sharing events." Journal of Consumer Behaviour 11(4): 303-315.

Anderson, C. (2012). Makers: the new industrial revolution. London, Random House Business.

Appadurai, A. (2000). "Grassroots Globalization and the Research Imagination." Public Culture 12(1): 1-19.

Asaro, P. M. (2000). "Transforming society by transforming technology: the science and politics of participatory design." Accounting Management and Information Technologies 10: 257-290.

Atkinson, P. (2006). "Do It Yourself: Democracy and Design." Journal of Design History 19(1): 1-10.

Bauer, M. (1995). Resistance to New Technology. Cambridge, Cambridge University Press.

Bauwens, M. (2013). Thesis on digital labor in an emerging P2P economy. Digital labor: the internet as playground and factory. T. Scholz. New York, Routledge: 207-210.

Benford, R. D. and D. A. Snow (2000). "Framing processes and social movements: an overview and assessment." Annual Review of Sociology 26: 611-639.

Benkler, Y. and H. Nissenbaum (2006). "Commons-based Peer Production and Virtue" Journal of Political Philosophy 14(4): 394-419.

Bijker, W. E. (1995). Of bicycles, bakelites and bulbs. Cambridge, Mass., MIT Press.

Bijker, W. E. (2010). "How is technology made?-That is the question!" Cambridge Journal of Economics 34(1): 63-76.

Bijker, W. E. and J. Law, Eds. (1992). Shaping technology/building society: studies in sociotechnical change. Cambridge, Mass., MIT Press.

Birtchnell, T. and J. Urry (2012). "Fabricating Futures and the Movement of Objects." Mobilities: 1-18.

Bookchin, M. (1967). "Towards a liberatory technology." Anarchy 78(August).

Braun, V. and C. Herstatt (2008). "THE FREEDOM-FIGHTERS:: HOW INCUMBENT CORPORATIONS ARE ATTEMPTING TO CONTROL USER-INNOVATION." International Journal of Innovation Management 12(3): 543-572.

Buechler, S. M. (2000). Social movements in advanced capitalism. Oxford, Oxford University Press. 
Chesbrough, H., W. Vanhaverbeke, et al., Eds. (2006). Open innovation: researching a new paradigm. Oxford, Oxford University Press.

Cole, H. S. D., C. Freeman, et al. (1973). Models of doom. New York, Universe Books.

Coleman, G. (2010). "The hacker conference: a ritual condensation and celebration of a lifeworld." Anthropological Quarterly 83(1): 47-72.

Cooley, M. (1987). Architect or bee? The human price of technology. London, Hogarth Press.

Crossley, N. (2002). Making sense of social movements. Buckingham, Open University.

Currah, A. (2007). "Managing creativity: the tensions between commodities and gifts in a digital networked environment." Economy \& Society 36(3): 476494.

Dahlander, L. and D. M. Gann (2010). "How open is innovation?" Research Policy 39(6): 699-709.

Dant, T. (2005). Materiality and society. Maidenhead, Open University Press.

Darnovsky, M., B. Epstein, et al., Eds. (1995). Cultural politics and social movements. Philadelphia, PA, Temple University Press.

Edelman, M. (2001). "Social movements: changing paradigms and forms of politics." Annual Review of Anthropology 30: 285-317.

Eisenhardt, K. M. (1989). "Building theories from case study research." Academy of Management Review 14(4): 532-550.

Elliott, A., \& Turner, B. S. (2012). On society. Cambridge: Polity.

Expert Group on Science and Governance (2007). Taking the knowledge society seriously. A report to the Science, Economy and Society Directore, DGResearch, European Commission. Brussels.

Flyvbjerg, B. (2006). "Five mis-understandings about case study research." Qualitative Inquiry 12(2): 219-245.

Freeman, C. and L. Soete (1997). The economics of industiral innovation. London, Pinter.

Geels, F. W. and J. Schot (2007). "Typology of sociotechnical transition pathways." Research Policy 36(3): 399-417.

Gershenfeld, N. (2005). FAB: the coming revolution on your desktop - from personal computers to personal fabrication. New York, Basic Books.

Heiskanen, E., S. Hyysalo, et al. (2010). "Constructing innovative users and userinclusive innovation communities." Technology Analysis \& Strategic Management 22(4): 495 - 511.

Hess, D. J. (2005). "Technology- and Product-Oriented Movements: Approximating Social Movement Studies and Science and Technology Studies." Science, Technology \& Human Values 30(4): 515-535.

Hess, D. J. (2007). Alternative pathways in science and industry: activism, innovation and the environment in an er of globalization. cambridge, Mass., MIT Press.

Hienerth, C. (2006). "The commercialization of user innovations: the development of the rodeo kayak industry." R\&D Management 36(3): 273294. 
Hoogma, R., R. Kemp, et al. (2002). Experimenting for sustainable transport: the approach of strategic niche management. London, Spon Press.

Jamison, A. (2003). "The making of green knowledge: the contribution of activism." Futures 35: 703-716.

Jasanoff, S. (2004). The idiom of co-production. States of knowledge: the coproduction of science and social order. S. Jasanoff. London, Routledge.

Joly, P.-B., A. Rip, et al. (2010). Reinventing innovation. The governance of innovation: firms, clusters and institutions in a changing setting. M. J. Arentsen, W. v. Rossum and A. E. Steenge. Cheltenham, Edward Elgar: 1932.

Jones, B. (1997). Forcing the factory of the future: cybernation and societal institutions. Cambridge, Cambridge University Press.

Jorgensen, U. and P. Karnoe (1995). The Danish wind-turbine story: technical solutions to political visions? Managing technology in society: the approach of constructive technology assessment. A. Rip, T. J. Misa and J. Scott. London, Pinter.

Kemp, R., J. Schot, et al. (1998). "Regime shifts to sustainability through processes of niche formation: The approach of strategic niche management." Technology Analysis \& Strategic Management 10(2): 175 198.

Khoo, M. (2005). "Technologies aren't what they used to be: problematising closure and relevant social groups." Social Epistemology 19(3): 283-285.

Kolb, F. (2007). Protest and opportunities: the political outcomes of social movements. Frankfurt, Campus Verlag.

Leach, M., I. Scoones, et al. (2010). Dynamic sustainabilities: technology, environment, social justice. London, Earthscan.

Leach, M., I. Scoones, et al. (2005). Science and citizens. London, Zed Books.

MacKenzie, D. and J. Wajcman, Eds. (1985). The social shaping of technology: how the refrigerator got its hum. Milton Keynes, Open University Press.

Manyika, J., J. Sinclair, et al. (2012). Manufacturing the future: the next era of global growth and innovation, McKinsey Global Institute.

Marres, N. (2012). Material participation: technology, the environment and everyday publics. London, Palgrave Macmillan.

Marston, L. (2011). Personal manufacturing. NESTA. London, NESTA.

McAdam, D. (1988). "Micromobilization contexts and recruitment to activism." International Social Movement Research 1: 125-154.

McAdam, D., S. Tarrow, et al. (2001). Dynamics of contention. Cambridge, Cambridge University Press.

McLaughlin, P. (2012). "Ecological Modernization in Evolutionary Perspective." Organization \& Environment 25(2): 178-196.

Miller, B. A. (2002). Geography and social movements: comparing anti-nuclear movements in the Boston area. Minnesota, University of Minnesota Press.

Miller, D. (2005). Materiality: an introduction. Materiality. D. Miller. Durham, Duke University: 1-50.

Moilanen, J. (2011). "Peer-production communities survey 2011." Retrieved 24 May 2012, 2012, from http://blog.ossoil.com/2011/07/10/peerproduction-communities-survey-2011/. 
Mota, C. (2011). The rise of personal fabrication. Proceedings of the 8th ACM conference on Creativity and cognition. Atlanta, Georgia, USA, ACM: 279288.

Nelson, R. R., Ed. (1993). National innovation systems: a comparative study. Oxford, Oxford Univeristy Press.

Noble, D. (1984). Forces of production: a social history of industrial automation. New York, Knopf.

O'Mahony, S. (2003). "Guarding the commons: how community managed software projects protect their work." Research Policy 32: 1179-1198.

Oudshoorn, N. and T. Pinch, Eds. (2003). How users matter: the co-construction of users and technologies. Cambridge, Mass., MIT Press.

P2P Foundation (2012). A synthetic overview of the collaborative economy. Amsterdam, P2P Foundation.

Pepper, D. (1984). The roots of modern environmentalism. London, Croom Helm.

Scholz, T., Ed. (2013). Digital labour: the internet as playground and workplace. New York, Routledge.

Schor, J. B. (2010). Plenitude: The New Economics of rue Wealth. New York, Penguin Press.

Seyfang, G. and A. Smith (2007). "Grassroots innovations for sustainable development: Towards a new research and policy agenda." Environmental Politics 16(4): 584 - 603.

Siefkes, C., Ed. (2007). From exchange to contributions: generalizing peerproduction into the physical world. Berlin, Edition C.Siefkes.

Smith, A. (2005). "The alternative technology movement: an analysis of its framing and negotiation of technology development." Human Ecology Review 12(2): 106-119.

Smith, A. (2007). "Translating Sustainabilities between Green Niches and SocioTechnical Regimes." Technology Analysis \& Strategic Management 19(4): 427-450.

Smith, A., M. Fressoli, et al. (2013). "Grassroots innovation movements: contrbutions and challenges." \ournal of Cleaner Production in press.

Smith, A. and R. Raven (2012). "What is protective space? Reconsidering niches in transitions to sustainability." Research Policy 41(6): 1025-1036.

Snow, D. A., E. Rochford, et al. (1986). "Frame alignment processes, micromobilisation and movement participation." American Sociological Review 51(4): 464-481.

Snow, D. A., S. A. Soule, et al., Eds. (2004). Blackwell companion to social movements. Oxford, Blackwell.

Soderberg, J. (2012). "The unmaking of the working class and the rise of the maker." Re-public: re-imagining democracy http://www.republic.gr/en/?p=5399 15/10/2012.

Söderberg, J. (2011). "Free space optics in the Czech wireless community: shedding some light on the role of normativity for user-initiated innovations." Science Technology and Human Values 36: 423-.

Spaargaren, G. and B. V. Vliet (2000). "Lifestyles, consumption and the environment: The ecological modernization of domestic consumption." Environmental Politics 9(1): 50-76.

Stangler, D. and K. Maxwell (2012). "DIY Producer Society." Innovations: Technology, Governance, Globalization 7(3): 3-10. 
Star, S. L. (1999). "The ethnograhy of infrastructure." A,erican Behavioural Scientist 43(3): 377-391.

Troxler, P. (2010). Commons-based peer-production of physical goods: is there room for a hybrid innovation ecology? The 3rd Free Culture Research Conference. Berlin.

Truffer, N. (2003). "User-led innovation processes: the development of professional car sharing by environmentally concerned citizens." Innovation 16(2): 139-154.

van Hinte, E. (1997). Eternally yours: visions on product endurance. Rotterdam, 010 Publishers.

van Oost, E., S. Verhaegh, et al. (2009). "From Innovation Community to Community Innovation: User-initiated Innovation in Wireless Leiden." Science, Technology \& Human Values 34(2): 182-205.

Verbeek, P.-P. (2006). "Materializing Morality." Science, Technology \& Human Values 31(3): 361-380.

von Hippel, E. (2005). Democratizing innovation. Cambridge, M.A., MIT Press.

Von Hippel, E. and R. Katz (2002). "Shifting innovation to users via toolkits." Management Science 48(7): 821-833.

Wainwright, H. and D. Elliott (1982). The Lucas Plan. A new trade unionism in the making? London, Allison \& Busby.

Wajcman, J. (2002). "Addressing Technological Change: The Challenge to Social Theory." Current Sociology 50(3): 347-363.

Wark, M. (2013). Considerations on a Hacker manifesto. Gigital labor: the internet as playrgound and factory. T. Scholz. New York, Routledge.

Watson, M. and E. Shove (2008). "Product, Competence, Project and Practice." Journal of Consumer Culture 8(1): 69-89.

West, J. and K. Lakhani (2008). "Getting clear about communities in open innovation theory." Industry and Innovation 15: 223-231.

Winner, L. (1993). "Upon opening the black-box and finding it empty: social constructivism and the philosophy of technology." Science, Technology \& Human Values 18(3): 362-378. 
Recent papers in the SPRU Working Paper Series:

SWPS 2013-01. Gabriele Pellegrino and Maria Savona. September 2013. "Is money all? Financing versus knowledge and demand constraints to innovations". 